\title{
Inflammatory Microenvironment Changes the Secretory Profile of Mesenchymal Stem Cells to Recruit Mesenchymal Stem Cells
}

\author{
Junchao Xing ${ }^{a, b, c, c d}$ Tianyong Hou ${ }^{a, b, c, c d}$ Huiyong Jin ${ }^{a, b, c, c, d}$ Fei Luo ${ }^{a, b, c, d}$ \\ Zhengqi Chang ${ }^{a, b, c, d}$ Zhiqiang Lia,b,c,d Zhao Xie ${ }^{a, b, c, c d} \quad$ Jianzhong X $\mathrm{u}^{\mathrm{a}, \mathrm{b}, \mathrm{c}, \mathrm{d}}$
}

aNational and Local United Engineering laboratory of Tissue Engineering, Department of Orthopaedics, Southwest Hospital, the Third Military Medical University, ${ }^{\mathrm{b} C e n t e r}$ of Tissue Engineering Research and Application, the Third Military Medical University, 'Laboratory of Tissue Engineering in Chongqing City, ${ }^{\mathrm{d} C e n t e r}$ of Regenetive and Reconstructive Engineering Technology in Chongqing City, Chongqing, China

\section{Key Words}

Mesenchymal stem cells • Cell migration - Inflammatory microenvironment • Chemokine secretion

\begin{abstract}
Background/Aims: Human bone-marrow mesenchymal stem cells (hBMSCs) are widely transplanted into inflammatory microenvironment to accelerate tissue regeneration. Transplanted hBMSCs recruit host hBMSCs through a poorly understood mechanism. This study was aimed to determine whether and how inflammatory microenvironment influenced the host-hBMSCs-recruiting capability of transplanted hBMSCs. Methods: Proinflammatory factors, including IL-1 $\beta$, IL- 6 and TNF- $\alpha$, were utilized to mimic inflammatory microenvironment. hBMSCs were cultured and conditioned media (CM) were collected. The effects of inflammatory microenvironment on the host-hBMSCs-recruiting capability of cultured hBMSCs were revealed by transwell migration assays. Employing semi-quantitative and quantitative cytokine antibody assays, we examined the secretory profile of cultured hBMSCs. Results: CM from cultured hBMSCs exerted excellent host-hBMSCs-recruiting capability, which was significantly promoted by exposure to inflammatory microenvironment. Within inflammatory microenvironment, hBMSCs secreted more chemokines related to cell migration. Finally, 21 cytokines were verified as potential factors accounting for the enhanced host-hBMSCs-recruiting capability of cultured hBMSCs exposed to inflammatory microenvironment. Conclusion: These results strongly suggested that in clinic, inflammatory microenvironment might promote the host-hBMSCs-recruiting capacity of transplanted hBMSCs by increasing chemokines secretion. Modulation of such characteristics of hBMSCs might provide novel therapeutic ideas in the context of hBMSCs.
\end{abstract}

Copyright (C) 2014 S. Karger AG, Basel 


\section{Cellular Physiology Cell Physiol Biochem 2014;33:905-919

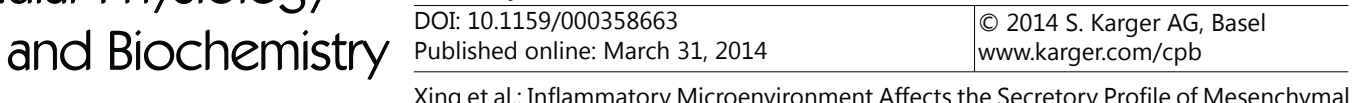 Stem Cells}

\section{Introduction}

Mesenchymal stem cells (MSCs)-based tissue engineering strategies hold great potential for various kinds of musculoskeletal diseases, especially those accompanied by large bone defects as a result of severe trauma, inflammation and tumor resection. Thereinto, MSCs are frequently transplanted with bioscaffolds into the defects to accelerate bone regeneration. Accumulating evidence indicate that successful application of MSCs transplantation, not confined to the field of bone tissue engineering, largely depends on the mobilization and homing of the endogenous stem cells, a result of indirect paracrine effects by proteins secreted from transplanted MSCs, rather than their direct transdifferentiation [1-4]. This notion is further reinforced by our previous findings that bone repair mediated by transplanted MSCs was largely attributed to the expansion and differentiation of endogenous MSCs [5]. Moreover, emerging new findings suggested that transplanted donor MSCs could recruit host stem/progenitor cells to the transplantation site for tissue repair [6, 7]. These observations have kindled much interest in mechanisms governing host MSCs migration induced by transplanted MSCs.

Currently, there is a general consensus that the homing of endogenous stem cells to the injury site is a prerequisite for tissue regeneration and determines the efficacy of MSCs transplantation [8]. In the early phase of wound healing, that is, inflammatory phase, an intricate cascade of growth factors and inflammatory mediators was released by cellular participants in a temporally and spatially controlled manner [9]. As a result, indigenous MSCs were attracted to the injured tissues and then exerted reparative property [10-13]. During growth, MSCs produce multifarious chemokines and cytokines spontaneously, some of which are important in dictating migration of stem cells, such as CC chemokine ligands (CCL2, CCL4, CCL5, CCL20) and CXC ligands (CXCL8, CXCL12) [14, 15]. After transplantation, the secretory property of MSCs may be mainly influenced by surrounding local inflammatory microenvironments. However, the molecular identities of secreted proteome (secretome) of transplanted MSCs are unclear, and moreover, how and to what extent inflammatory microenvironment affects transplanted-MSCs-induced tropism of endogenous MSCs are yet to be clarified. Establishing this information will provide new insights into the cellular mechanisms underlying the tissue regeneration mediated by transplanted MSCs and the modulation of endogenous stem/progenitor cells homing for in situ tissue regeneration.

IL-1 $\beta$, IL- 6 and TNF- $\alpha$ are three major pro-inflammatory factors (PF) induced by inflamed tissues, and their concentrations rise and peak in the inflammatory phase of transplantation and tissue regeneration [16]. They play important roles in inflammatory diseases by inducing various inflammatory cytokines and chemokines [16, 17]. Moreover, IL-1 $\beta$, IL- 6 and TNF- $\alpha$ induce migration of MSCs by binding to the respective receptors and activating the corresponding downstream signals [18-21]. Thus, IL-1 $\beta$, IL-6 and TNF- $\alpha$ may regulate the secretome of MSCs and are ideally suited for imitating the in vivo inflammatory microenvironment.

Therefore, this study was aimed to explore the secretome of human bone-marrow mesenchymal stem cells (hBMSCs) in inflammatory microenvironment and seek the factors involved with hBMSCs migration. PF including IL- $1 \beta$, IL- 6 and TNF- $\alpha$ were added into the culture of hBMSCs and the resulting conditioned media (CM) were collected. We then evaluated the effects of inflammatory microenvironment on the host-hBMSCs-recruiting capacity and secretome of cultured hBMSCs by Transwell Migration Assay and Human Cytokine Microarray.

\section{Materials and Methods}

Cell isolation and culture

All protocols involving human subjects were approved by Ethics Committee, Southwest Hospital, Third Military Medical University, with all subjects providing informed consents. Briefly, nucleated cells 


\section{Cellular Physiology $\quad$ Cell Physiol Biochem 2014;33:905-919

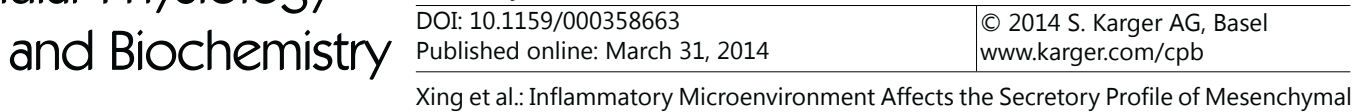 Stem Cells}

were isolated from iliac crest bone marrow aspirates of healthy donors (15 donors in total, aged 23 to 45, 6 male and 9 female) by Ficoll (Sigma-Aldrich, USA) gradient centrifugation. For each donor, cells were kept separate and resuspended in basic culture medium containing Dulbecco's modified Eagle's medium/ F12 (DMEM/F12; 1:1; Hyclone) containing 10\% fetal bovine serum (FBS; Gibco, USA), and 100 units/ml penicillin/streptomycin (Gibco, USA). Cells were placed in $75-\mathrm{cm}^{2}$ flasks (Corning Costar Corp, USA) and incubated with basic culture medium at $37^{\circ} \mathrm{C}$ in $95 \%$ humidified air and $5 \% \mathrm{CO}_{2}$. Medium was replaced every 3 days and cultures with 80\%-90\% confluence were detached with $0.25 \%$ trypsin-EDTA (Hyclone, USA). Before use, hBMSCs of passage 4 (P4) were characterized by morphology, immunophenotypic analysis, and osteogenic and adipogenic differentiation. For immunophenotypic analysis, cells were harvested and washed with fluorescence-activated cell sorting (FACS) buffer (2\% FBS and 0.1\% NaN3 (KeLong Chemical, Chengdu, China) in phosphate buffered saline (PBS; Zhongshan Golden Bridge Biotechnology, Beijing, China)). Then, cells were incubated with specific fluorescence-conjugated antibodies (1:100 dilution) for $1 \mathrm{~h}$ and analyzed by flow cytometry with a FACSCalibur flow cytometer (BD Biosciences, USA). Human monoclonal antibodies were used as follows: anti-CD29-PE, anti-CD44-PE, anti-73-APC, anti-90-APC, antiCD105-PE, anti-CD31-PE, anti-CD34-APC, and anti-45-APC, and the recommended isotype control for each fluorochrome (all from BD biosciences, USA). For analysis of multilineage differentiation capacity, cells were detached from cultures reaching $80-90 \%$ confluency, washed and seeded at $5 \times 10^{4} /$ well in a 24 -well culture plate (Corning Costar Corp, USA). Osteogenesis was induced by culture in DMEM/F12 with 50 $\mu$ M ascorbic acid, $10 \mathrm{mM} \beta$-glycerophosphate, and $0.2 \mu \mathrm{M}$ dexamethasone (all from Sigma-Aldrich, USA). On day 14, the calcium deposits were shown using the Leukocyte Alkaline Phosphatase Kit (Sigma-Aldrich, USA) according to the manufacturer's recommendations. To induce adipogenic differentiation, cultures were stimulated for 21 days in DMEM/F12 supplemented with 1\% FBS, $1 \mu \mathrm{M}$ dexamethasone, $50 \mu \mathrm{M}$ 3-isobutyl-1-methylxanthine (IBMX), $100 \mathrm{ng} / \mathrm{ml}$ insulin (all from Sigma-Aldrich, USA). The medium was changed twice a week. After Oil Red 0 (Sigma-Aldrich, USA) staining, lipid droplets were visualized with light microscope. Finally, cells had a spindle-shaped morphology, were homogeneously CD29+, CD44+, CD73 ${ }^{+}, \mathrm{CD}^{+} 0^{+}, \mathrm{CD} 105^{+}, \mathrm{CD} 31^{\text {; }}$ CD34, CD45- (Fig. 1A), and were able to differentiate into osteoblasts (Fig. 1B) and lipoblasts (Fig. 1C).

\section{Preparation of conditioned media}

Confluent hBMSCs (equivalent to transplanted hBMSCs) from 15 donators were separately washed twice with serum-free DMEM/F12 and incubated with serum-free medium alone or supplemented with

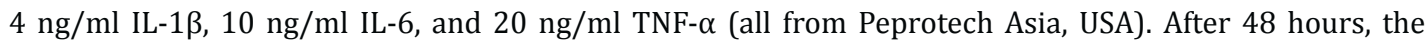
supernatants were collected, centrifuged, aliquoted, and stored at $-80^{\circ} \mathrm{C}$. Serum-free medium with the presence or absence of IL-1 $\beta$, IL-6, and TNF- $\alpha$ served as control. The grouping of CM was detailed in Table 1.

\section{Migration assay}

Migration assays were performed in transwell inserts ( $8 \mu \mathrm{m}$ pores; Corning Costar Corp, USA). For each cell batch, $700 \mu \mathrm{l}$ of CM from each group was added into the bottom compartment. Non-treated hBMSCs $\left(2 \times 10^{4}\right.$, equivalent to endogenous hBMSCs $)$ in $200 \mu \mathrm{l}$ serum-free medium were seeded into the top chamber and allowed to migrate at $37^{\circ} \mathrm{C}$ for 36 hours. Then, cells on the upper side of the filter (non-migrating cells) were removed with a cotton wool swab (Norgen Biotek, Canada). Migrated cells on the lower face were washed with PBS and fixed with 4\% paraformaldehyde (Boster Biological Technology, Wuhan, China). The membrane was then placed onto glass slides with the bottom side upwards and migrated cells were stained with 4', 6 diamidino-2 phenyilindole (DAPI; Invitrogen, USA), and observed under a microscope. For each group, the number of migrated cells was counted on 10 random high power fields (200× magnification) and averaged. Migration assay was separately conducted on 15 batches of hBMSCs obtained from 15 donators.

\section{Cytokine antibody assay}

To screen chemokines associated with hBMSCs migration, high-throughput RayBio Human Cytokine Antibody Assays (RayBiotech, Norcross, USA) were employed as per manufacturer's instructions. The assay was repeated in quadruplicate, on 4 batches of CM randomly selected from 15 batches. Using this assay, 262 different human cytokines can be screened simultaneously. Briefly, the membranes were blocked with blocking buffer for 1 hour and then incubated with CM sample (100 $\mu$ l from each group) for 2 hours at room temperature. After extensive wash with wash buffer I ( 5 times, 5 min each) and wash buffer II (twice, 5 min each), membranes were incubated with a cocktail of biotin-conjugated antibodies at room temperature. 
Xing et al.: Inflammatory Microenvironment Affects the Secretory Profile of Mesenchymal Stem Cells
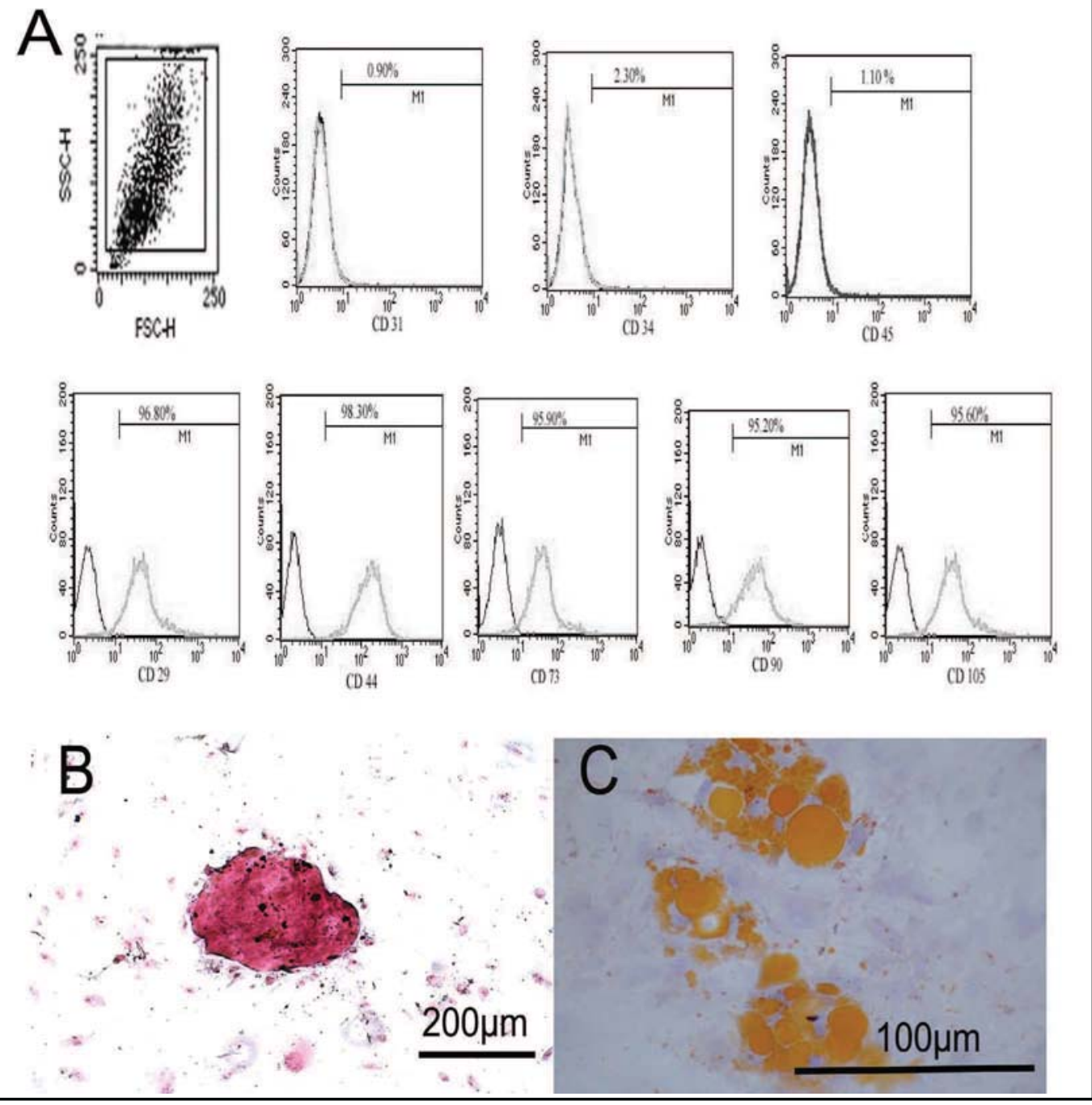

Fig. 1. Characterization of hBMSCs. (A) Histogram analysis of cell surface markers showed that hBMSCs were positive for CD29, CD44, CD73, CD90, CD105, and negative for CD31, CD43, and CD45. After induction of osteogenic and adipogenic differentiation, calcium deposits (B) and lipid droplets (C) were observed, suggesting that cultured hBMSCs were able to differentiate into osteoblasts and lipoblasts. hBMSCs, human bone-marrow mesenchymal stem cells.

After $90 \mathrm{~min}$, membranes were repeatedly washed and then horseradish peroxidase-conjugated streptavidin (Cy3 equivalent) was added an incubated at room temperature for $1 \mathrm{~h}$, followed by a set of washes. Finally, fluorescent signals were detected by a GenePix ${ }^{\mathrm{TM}}$ 4000B laser scanner (Axon Instruments, Sunnyvale, CA94089, USA). The relative protein levels were obtained by subtracting the background staining and normalizing to the positive controls on the same membrane.

\section{Quantitative human cytokine array}

To further quantify the levels of screened chemokines, a custom Quantibody human cytokine array was performed on the same 4 batches of samples. The array is a multiplex sandwich enzyme-linked immunosorbent assay (ELISA)-based system, which spotted the membrane with 42 cytokine or chemokinespecific antibodies per our request. The proteins of interest are shown in Table 2 . The protocol was similar to that of cytokine antibody assay. Each antibody toward cytokine or chemokine, together with the positive, negative and internal controls, was arrayed in quadruplicate. Data were extracted and analyzed with RayBio QAM-TH17-1 software (RayBiotech, Inc.). When the cytokine levels were below the sensitivity, a value of 0 was used for the comparisons of the levels. 


\section{Cellular Physiology and Biochemistry \\ Cell Physiol Biochem 2014;33:905-919

\begin{tabular}{l|l}
\hline DOI: $10.1159 / 000358663$ & (c) 2014 S. Karger AG, Basel
\end{tabular} \\ Xing et al.: Inflammatory Microenvironment Affects the Secretory Profile of Mesenchymal Stem Cells}

Table 1. The grouping of conditioned media. * Proinflammatory factors included $4 \mathrm{ng} / \mathrm{ml} \mathrm{IL-1 \beta}, 10$ $\mathrm{ng} / \mathrm{ml} \mathrm{IL-6,} \mathrm{and} 20 \mathrm{ng} / \mathrm{ml}$ TNF- $\alpha$. hBMSCs, human bone-marrow mesenchymal stem cells

\begin{tabular}{llc}
\hline Groups & hBMSCs & Pro-inflammatory factors* \\
\hline A & Yes & Yes \\
B & Yes & No \\
C & No & No \\
D & No & Yes \\
\hline
\end{tabular}

Table 2. Proteins detected by Quantibody human cytokine array

\begin{tabular}{lllllll}
\hline ANG & ENA-78 & IGF-II & IL-2 R $\alpha$ & MCP-3 & MIP-3 $\beta$ & RANTES \\
\hline ANG-1 & EOT2 & IL-10 & IL-6 & MDC & NAP-2 & SDF-1 \\
Cathepsin S & GCP-2 & IL-11 & IL-8 & MIP-1 $\alpha$ & OPG & TNF RII \\
CD14 & GM-CSF & IL-16 & LAP & MIP-1 $\beta$ & OPN & TRAIL R3 \\
CXCL16 & GRO & IL-1 $\alpha$ & MCP-1 & MIP-1 $\delta$ & PDGF-AA & u PAR \\
EGF & IGFBP-3 & IL-1 $\beta$ & MCP-2 & MIP-3 $\alpha$ & RANK & VEGF \\
\hline
\end{tabular}

Fig. 2. Migration capacity of hBMSCs toward different CM. (A) showed the images of in vitro migration assay using transwell culture system. CM $(200 \mathrm{ul})$ and hBMSCs $\left(2 \times 10^{4}\right)$ were added into the bottom and top chamber, respectively. Migration was terminated after 36 hours. Migrated hBMSCs were stained with DAPI. Bar $=100$ um. (B) Quantification of transwell results. The number of migrated cells was counted on 10 random high power fields for each CM. Bars are mean \pm SD; $n=10$; ${ }^{*} \mathrm{p}<0.0083$. hBMSCs, human bonemarrow mesenchymal stem cells. CM, conditioned media. DAPI, 4', 6 diamidino-2 phenyilindole. DMEM/ F12, Dulbecco's modified Eagle's medium/F12. PF, pro-inflammatory factors.

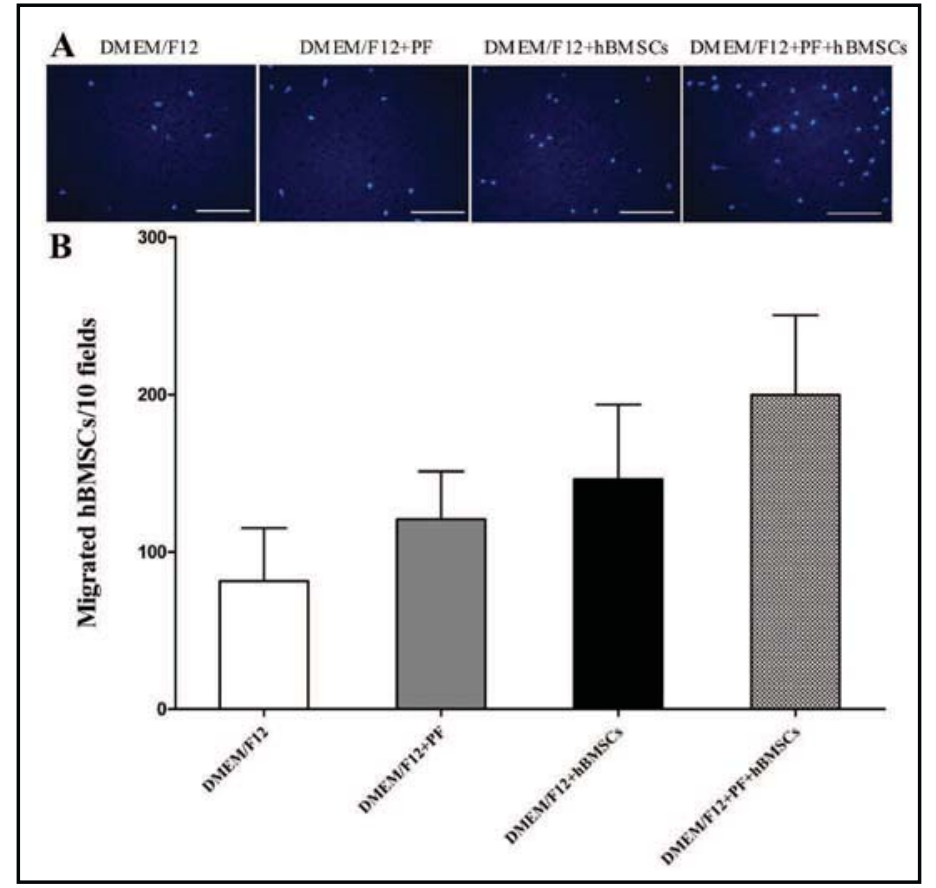

Statistical analysis

All comparable values were expressed as mean \pm SD. Between any two groups, the mean numbers of migrated cells toward CM were compared using one-way ANOVA (SPSS version 13.0). Using bonferroni correction, $\mathrm{P}<0.0083(0.05 / 6)$ was considered statistically significant. The results of cytokine antibody arrays from different CM were compared by ANOVA tests with Post Hoc Test (SPSS version 13.0). P $<0.05$ was considered statistically significant.

\section{Results}

CM from PF-stimulated hBMSCs facilitated migration of hBMSCs

To investigate the hBMSCs-recruiting capacity of hBMSCs in the inflammatory microenvironment, migration assays were performed. As shown in Figure 2, the chemotactic activity of hBMSCs ${ }^{+}$DMEM/F12 was markedly higher than hBMSCs- DMEM/F12 $(\mathrm{P}<0.0083)$, while slightly higher than $\mathrm{PF}^{+}$DMEM/F12 $(\mathrm{P}>0.0083)$. This suggested that the bioactive factors released by non-treated hBMSCs had analogous chemotatic power to PF. Moreover, 


\section{Cellular Physiology $\quad$ Cell Physiol Biochem 2014;33:905-919

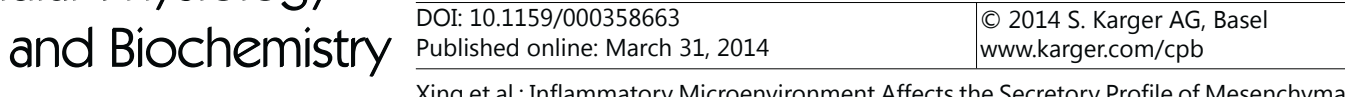 Stem Cells}

Table 3. The fold change of human cytokines between samples. \#DIV/0!: the value of control is 0 . PF, proinflammatory factors, include $4 \mathrm{ng} / \mathrm{ml} \mathrm{IL-}-1 \beta, 10 \mathrm{ng} / \mathrm{ml} \mathrm{IL-6}$, and $20 \mathrm{ng} / \mathrm{ml}$ TNF- $\alpha$. hBMSCs, human bonemarrow mesenchymal stem cells. DMEM/F12, Dulbecco's modified Eagle's medium/F12

\begin{tabular}{|c|c|c|c|c|c|c|c|c|}
\hline Cytokine name & $\begin{array}{l}\text { Fold change } \\
\text { PF-stimula- } \\
\text { ted hBMSCs } \\
\text { versus non- } \\
\text { treated } \\
\text { hBMSCs }\end{array}$ & $\begin{array}{l}\text { Fold change } \\
\text { non-treated } \\
\text { hBMSCs versus } \\
\text { DMEM/F12 }\end{array}$ & Cytokine name & $\begin{array}{l}\text { Fold change } \\
\text { PF-stimula- } \\
\text { ted hBMSCS } \\
\text { versus non- } \\
\text { treated } \\
\text { hBMSCs }\end{array}$ & $\begin{array}{l}\text { Fold change } \\
\text { non-treated } \\
\text { hBMSCs versus } \\
\text { DMEM/F12 }\end{array}$ & Cytokine name & $\begin{array}{l}\text { Fold change } \\
\text { PF-stimula- } \\
\text { ted hBMSCs } \\
\text { versus non- } \\
\text { treated } \\
\text { hBMSCs }\end{array}$ & $\begin{array}{l}\text { Fold change } \\
\text { non-treated } \\
\text { hBMSCs versu } \\
\text { DMEM/F12 }\end{array}$ \\
\hline Angiogenin & 0.889747779 & 4.957937582 & MIP-3-alpha & 0.993957347 & 1.112664564 & Lymphotactin & 0.631396288 & 1.059306047 \\
\hline BDNF & 0.904458467 & 0.761156891 & NAP-2 & 1.511251805 & 0.015094287 & MIF & 0.566395035 & 1.633601567 \\
\hline BLC & 0.715342714 & 0.913535291 & NT-3 & 1.058963291 & 1.44301381 & MIP-1alpha & 0.583886288 & 0.042156496 \\
\hline BMP-4 & 0.825264182 & 1.315416773 & PARC & 1.077860127 & 1.007432788 & MIP-1beta & 0.933938325 & 0.178783873 \\
\hline BMP-6 & 0.918090508 & 0.712450333 & PDGF-BB & 1.266331735 & 1.025451525 & MIP-3beta & 0.718471822 & 1.111520373 \\
\hline CK beta 8-1 & 0.974971068 & 1.928618577 & RANTES & 1.635487318 & 1.119618717 & MSP-alpha & 0.863967507 & 0.938573643 \\
\hline CNTF & 0.794643439 & 0.905878859 & SCF & 0.95971854 & 0.844791612 & NT -4 & 0.805412504 & 0.978713963 \\
\hline EGF & 0.808392819 & 1.520933608 & SDF -1 & 1.052782156 & 1.293907659 & Osteoprotegerin & 4.025217328 & 15.29335487 \\
\hline Eotaxin & 0.808467761 & 1.220677615 & TGF-beta 1 & 1.151268229 & 0.99506587 & Oncostatin M & 0.666910393 & 0.936968942 \\
\hline Eotaxin-2 & 1.740775411 & 0.557144446 & TNF-alpha & 1.199898604 & 0.972579523 & PIGF & 0.341901704 & 1.172148086 \\
\hline Eotaxin-3 & 0.929202889 & 1.12978248 & TNF-beta & 1.037930956 & 0.921504639 & sgp130 & 0.824991376 & 1.139108678 \\
\hline FGF-6 & 0.200523504 & 1.042632582 & Acrp30 & 0.702020963 & 1.533860771 & STNF RII & 0.513428148 & 1.887619116 \\
\hline FGF-7 & 1.374645784 & 0.581291424 & AgRP & 0.823724458 & 0.972409847 & sTNF-RI & 0.695014063 & 0.858524009 \\
\hline Flt-3 Ligand & 0.802973248 & 0.983829719 & Angiopoietin-2 & 0.729638115 & 1.032435147 & TECK & 0.69214484 & 0.878908901 \\
\hline Fractalkine & 0.958072749 & 0.898988682 & Amphiregulin & 0.659518064 & 1.313657454 & TIMP-1 & 0.635060763 & 22.78806399 \\
\hline GCP-2 & 57.69076413 & \#DIV/0! & Axl & 0.465371274 & 1.122011362 & TIMP-2 & 0.698226636 & 23.48340668 \\
\hline GDNF & 0.663295209 & 1.004251093 & bFGF & 0.414165373 & 0.995452735 & Thrombopoietin & 0.586042764 & 1.05922697 \\
\hline GM-CSF & 1.586538209 & 0.638477147 & b-NGF & 0.684566799 & 1.037072947 & TRAIL R3 & 0.501979657 & 1.389567918 \\
\hline $1-309$ & 0.548993311 & 2.049280867 & BTC & 0.575345398 & 0.82795766 & TRAIL R4 & 0.701972925 & 0.900707713 \\
\hline IFN-gamma & 1.031546017 & 1.016718396 & CCL-28 & 0.5394139 & 1.221745706 & UPAR & 0.755323768 & 1.043584781 \\
\hline IGFBP-1 & 1.448151959 & 2.628670032 & CTACK & 0.670110267 & 1.067962003 & VEGF & 0.838931625 & 1.30075603 \\
\hline IGFBP-2 & 1.149439575 & 38.13843236 & Dtk & 0.737139397 & 1.01619849 & VEGF-D & 0.707191467 & 0.771221603 \\
\hline IGF-I & 1.464649326 & 1.061876271 & EGF-R & 0.624475322 & 0.667340091 & Activin A & 0.585903658 & 1.512167322 \\
\hline IL-10 & 0.899647374 & 1.048102546 & ENA-78 & 2.092098706 & 0.808196644 & ALCAM & 0.680879691 & 0.730914267 \\
\hline $\mathrm{IL}-13$ & 1.664292718 & 1.08484795 & Fas/TNFRSF6 & 0.842268758 & 1.04039735 & B7-1(CD80) & 0.486161595 & 0.525564399 \\
\hline IL-15 & 1.004109858 & 1.060629504 & FGF-4 & 0.876215881 & 0.973825291 & BMP-5 & 1.0836273 & 0.518948807 \\
\hline IL-16 & 0.629166925 & 0.896875073 & FGF-9 & 0.63070869 & 1.049350371 & BMP.7 & 0.48112035 & 0.794873022 \\
\hline IL-1alpha & 0.899362855 & 1.085878195 & GCSF & 0.59444537 & 1.009481191 & Cardiotrophin-1 & 0.632863925 & 0.720691461 \\
\hline IL-1beta & 0,737584273 & 1.026818534 & GITR & 0.012448013 & 0.945934707 & CD14 & 0.313269861 & 0.614069687 \\
\hline IL-1ra & 0.558788747 & 1.130744307 & GRO & 32.85759626 & 0.917788156 & $\begin{array}{l}\text { CXCL-16 } \\
\text { DR6 }\end{array}$ & 2.090980185 & 1.324202816 \\
\hline $\mathrm{IL}-2$ & 1.040046888 & 1.008333415 & HCC-4 & 0.874583964 & 1.055798644 & (TNFRSF21) & 0.13365761 & 0.82225184 \\
\hline IL-3 & 0.367959245 & 0.898659159 & HGF & 0.475072046 & 1.127111414 & Endoglin & 0.747027164 & 0.953210301 \\
\hline $\mathrm{IL}-4$ & 1.614572963 & 0.972551248 & ICAM-1 & 0.811149535 & 0.958661122 & ErbB3 & 0.648441592 & 1.118563846 \\
\hline IL. 5 & 1.091852805 & 0.94305161 & IGFBP-3 & 1.794803172 & 0.986009985 & E-Selectin & 0.746879772 & 1.127185175 \\
\hline IL-6 & 29.26752243 & 1.266425233 & IGFBP-6 & 0.738098529 & 1.186117567 & Fas Ligand & 0.433372087 & 1.378502925 \\
\hline IL-7 & 1.246123343 & 0.938424384 & IGF-I SR & 0.561306111 & 0.978412377 & ICAM-2 & 0.521098605 & 1.159341476 \\
\hline Leptin & 1.946985043 & 0.942626594 & IL-1 R4/ST2 & 0.57279091 & 1.545534087 & IGF-II & 1.247919984 & 1.235030765 \\
\hline LIGHT & 0.800848201 & 1.035803497 & IL-1 RI & 0.776620672 & 1.073798552 & $\| \mathrm{L}-1 \mathrm{R}$ II & 0.680982521 & 0.773099279 \\
\hline MCP-1 & 11.50214058 & 0.752973 & IL-11 & 0.880680283 & 0.960425923 & IL-10 Rbeta & 1.206928311 & 0.38699947 \\
\hline MCP-2 & 30.02210012 & 0.935779428 & IL-12 p 40 & 0.427943483 & 1.050386109 & IL-13 Ralpha2 & 0.622323875 & 0.714083369 \\
\hline MCP-3 & 4.853721864 & 1.049501181 & Il-12 p 70 & 0.54323907 & 1.063832996 & IL-18 BPalpha & 0.549792775 & 0.453782966 \\
\hline MCP-4 & 1.615995807 & 1.680460662 & IL-17 & \#DIV/0! & \#DIV/0! & IL-2 Ralpha & HDIV/0! & 0 \\
\hline M.CSF & 1.229757558 & 2.354878804 & IL-2 Rapha & 0.794347255 & 0.98043179 & IL-2 Rbeta & 0.348203319 & 0.70866519 \\
\hline MDC & 1.645842015 & 0.850304731 & IL-6 R & 0.726914885 & 1.123405165 & IL-2 Rgamma & 0.155599091 & 1.367406326 \\
\hline MIG & 0.98631027 & 1.133900505 & IL-8 & 0.971004697 & 1.166891817 & IL-21R & 0.765273517 & 0.965227995 \\
\hline MIP-1-delta & 11.02025193 & "DIV/0! & 1-TAC & 0.654058563 & 1.058672011 & IL-5 Ralpha & 0.601296992 & 1.039794371 \\
\hline
\end{tabular}


Cell Physiol Biochem 2014;33:905-919 DOI: $10.1159 / 000358663$ C) 2014 S. Karger AG, Basel www.karger.com/cpb

Xing et al.: Inflammatory Microenvironment Affects the Secretory Profile of Mesenchymal Stem Cells

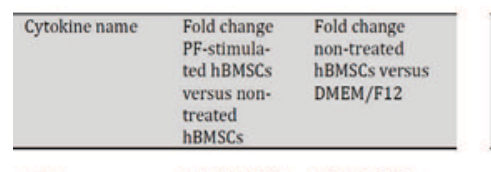

\begin{tabular}{lll}
\hline IL-9 & 0.583002994 & 1.293515615 \\
IP-10 & 0.663547222 & 1.078963 \\
LAP & 0.467579495 & 1.422041323
\end{tabular}

$\begin{array}{lll}\text { Leptin R } & 0.74649695 & 0.814497732\end{array}$

LIF $\quad 0.564190306 \quad 0.971019602$

$\begin{array}{lll}\text { L-Selectin } & 0.674612873 & 0.752368059\end{array}$

$\begin{array}{lll}\text { M-CSF R } & 0.738655308 & 0.728490799\end{array}$

$\begin{array}{lll}\text { MMP-1 } & 1.527944695 & 0.568866045\end{array}$

$\begin{array}{lll}\text { MMP.13 } & 0.69370569 & 0.459102033\end{array}$

$\begin{array}{lll}\text { MPIF-1 } & 0.328881054 & 0.532540769\end{array}$

$\begin{array}{lll}\text { NGF R } & 0.414444779 & 1.514896312\end{array}$

$\begin{array}{lll}\text { PDGF AA } & 0.682920472 & 0.878983086\end{array}$

$\begin{array}{lll}\text { PDGF-AB } & 0.737815001 & 1.231036023\end{array}$

$\begin{array}{lll}\text { PDGF Ralpha } \quad 1.24772856 & 2.094149626\end{array}$

$\begin{array}{lll}\text { PDGF Rbeta } \quad 0.622926138 & 1.22498058\end{array}$

$\begin{array}{lll}\text { PECAM-1 } & 0.271066168 & 1.11318888\end{array}$

$\begin{array}{lll}\text { Prolactin } & 0.675661601 & 1.026199587\end{array}$

$\begin{array}{lll}\text { SCF R } & 0.748637136 & 0.613658771\end{array}$

$\begin{array}{lll}\text { SDF-1beta } & 0.625923238 & 0.457360372\end{array}$

$\begin{array}{lll}\text { Siglec-5 } & 1.654131577 & 0.149208161\end{array}$

$\begin{array}{lll}\text { TGF-alpha } \quad 0.472823454 & 0.952926069\end{array}$

$\begin{array}{lll}\text { TGF beta2 } & 0.395344872 & 0.54059149\end{array}$

$\begin{array}{lll}\text { Tie-1 } & 0.484172931 & 0.63996041\end{array}$

$\begin{array}{lll}\text { Tie-2 } & 0.257493028 & 1.149726687\end{array}$

$\begin{array}{lll}\text { TIMP-4 } & \mathbf{0 . 6 6 7 4 3 8 1 1 4} & 1.482364085\end{array}$

$\begin{array}{lll}\text { VE-Cadherin } \quad 0.539558296 & 0.783078291\end{array}$

$\begin{array}{lll}\text { VEGF R2 } & 0.693335029 & 1.14258002\end{array}$

$\begin{array}{lll}\text { VEGF R3 } & 0.428364565 & 1.285062802\end{array}$

Adiposin $\quad 1.0167339 \quad 3.569529502$

$\begin{array}{lll}\text { BCAM } & 0.471544361 & 0.455275046\end{array}$

$\begin{array}{lll}\text { CD30 } & 1.018756566 & 1.90929455\end{array}$

$\begin{array}{lll}\text { CD40 } & 0.616774229 & 0.760168968\end{array}$

$\begin{array}{lll}\text { Fcr RIIB/C } & 0.925308382 & 0.850352884\end{array}$

$\begin{array}{lll}\text { Ferritin } \quad 1.019243136 & 0.975670774\end{array}$

$\begin{array}{lll}\text { FLRG } & 0.527558559 & 1.510472933\end{array}$

$\begin{array}{lll}\text { Follistatin } \quad 0.881887071 & 0.925736191\end{array}$

$\begin{array}{lll}\text { Furin } & 0.657290712 & 1.101755409\end{array}$

$\begin{array}{lll}\text { Galectin-7 } & 0.652300334 & 0.934287606\end{array}$

$\begin{array}{lll}\text { GDF-15 } & 1.075727971 & 0.83494794\end{array}$

Growth Hormon $\quad 0.792880054 \quad 0.743246021$

IL-10 R alpha $\quad 1.934381384 \quad 1.775826287$

$\begin{array}{lll}\text { IL-22 } & 1.418791867 & 0.875127392\end{array}$

$\begin{array}{lll}\text { IL-28A } & 1.802504352 & 1.156569855\end{array}$

$\begin{array}{lll}\text { IL29 } & 0.745802608 & 0.586403837\end{array}$

$\begin{array}{lll}\text { IL-31 } & 1.00525282 & 0.739772141\end{array}$

Insulin $\quad 0.904100304 \quad 0.807890863$

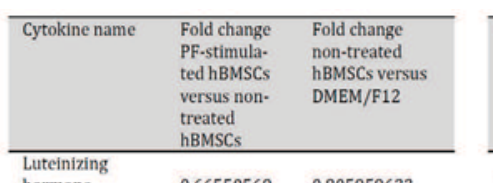

\begin{tabular}{lll} 
hormone & 0.66550569 & 0.805959633 \\
\hline
\end{tabular}

$\begin{array}{lll}\text { LIMPII } & 0.755250157 & 0.985658627\end{array}$

$\begin{array}{lll}\text { LYVE-1 } & 1.288127911 & 0.86445011\end{array}$

$\begin{array}{lll}\text { Marapsin } \quad 0.941651087 & 1.239442593\end{array}$

$\begin{array}{lll}\text { MICA } & 0.883858995 & 0.599550177\end{array}$

$\begin{array}{lll}\text { MICB } & 0.933372835 & 0.952254675\end{array}$

$\begin{array}{lll}\text { MMP-2 } & 1.005746665 & 0.740642525\end{array}$

$\begin{array}{lll}\text { MMP-7 } & 1.046869243 \quad 3.322310756\end{array}$

$\begin{array}{lll}\text { MMP-8 } & 0.912159816 & 1.237931078\end{array}$

$\begin{array}{lll}\text { MMP-10 } & 0.794950259 & 0.908251571\end{array}$

$\begin{array}{lll}\text { NCAM-1 } & 0.827307741 & 0.595159172\end{array}$

$\begin{array}{lll}\text { Nidogen-1 } \quad 0.777277737 & 1.40015797\end{array}$

$\begin{array}{lll}\text { NrCAM } & 0.732178039 & 1.269672901\end{array}$

$\begin{array}{lll}\text { NRG1-beta1 } & 0.414476244 & 0.903743588\end{array}$

$\begin{array}{lll}\text { Osteopontin } & 0.977483932 & 0.919782223\end{array}$

$\begin{array}{lll}\text { PAI-I } & 1.071933648 & 1.335345637\end{array}$

$\begin{array}{lll}\text { Platelet factor } 4 \quad 1.088369294 & 1.041528551\end{array}$

$\begin{array}{lll}\text { PSA-total } & 1.064775703 & 0.698427877\end{array}$

$\begin{array}{lll}\text { RAGE } & 0.799187312 & 0.9142585\end{array}$

$\begin{array}{lll}\text { RANK } & 0.96666594 & 3.523880296\end{array}$

$\begin{array}{lll}\text { Resistin } & 0.7441992 & 0.774535836\end{array}$

$\begin{array}{lll}\text { SAA } & 1.0483143 & 1.974528077\end{array}$

Siglec-9

TACE

TIM-1

TRAIL R2

Trappin-2

TREM-1

TSH

TSLP

VCAM-1

VEGF-C

XEDAR

4-1BB

ACE-2

Alpha-
fetoprotein

Angiopoietin-1

Angiostatin

ANGPTL4

Bate2 M

BCMA

beta IG-H3

CA125

CA15-3

CA19-9

Carbonic

Carbonic
Anhydrase IX $\begin{array}{lll}\text { Cathepsin S } \quad 1.585653391 & 1.230665704\end{array}$

$\begin{array}{lll}\text { CCL14a } & 0.911029948 & 2.624213633\end{array}$

$\begin{array}{lll}\text { CCL21 } & 1.266066433 & 0.894784548\end{array}$

$\begin{array}{llll}\text { CD23 } & 1.02372928 & 1.159702113\end{array}$

$\begin{array}{lll}\text { CD40 Ligand } \quad 0.865854035 & 0.981910821\end{array}$

$\begin{array}{lll}\text { CEA } & 0.831824628 & 0.964092822\end{array}$

$\begin{array}{lll}\text { CEACAM-1 } & 0.990579951 & 1.183104174\end{array}$

$\begin{array}{lll}\text { Cripto-1 } & 0.941891558 & 1.299384256\end{array}$

$\begin{array}{lll}\text { CRP } & 0.999561922 & 1.19669486\end{array}$

DAN $\quad 1.47639869 \quad 2.504170326$

$\begin{array}{lll}\text { DKK-1 } & 1.187386682 & 1.413837792\end{array}$

$\begin{array}{lll}\text { DKK-4 } & 1.305625749 & 1.137421051\end{array}$

$\begin{array}{lll}\text { DPPIV } & 0.855377425 & 2.662576548\end{array}$

$\begin{array}{lll}\text { E-Cadherin } & 1.043648232 & 0.877605871\end{array}$

$\begin{array}{lll}\text { EDA-A2 } & 1.457171595 & 3.152281199\end{array}$

$\begin{array}{lll}\text { ЕрСАM } & 0.909981583 & 3.08876758\end{array}$

$\begin{array}{lll}\text { ErbB2 } & 1.765120525 & 2.061972387\end{array}$

$\begin{array}{lll}\text { Erythropoietin R } & 1.38934688 & 1.137480276\end{array}$

FSH 0.459633554 \#DIV/0!

$\begin{array}{lll}\text { HB-EGF } & 1.18791524 & 1.016429682\end{array}$

hCGa, intact $\quad 1.007988248 \quad 1.074445918$

$\begin{array}{lll}\text { HVEM } & 0.993453577 & 1.231649235\end{array}$

IL-13 R alpha1 $\quad 1.161259609 \quad 1.43433544$

$\begin{array}{lll}\text { IL-17B } & 0.908452202 & 40.77407203\end{array}$

$\begin{array}{lll}\text { IL-17C } & 1.088914743 & 1.227454764\end{array}$

$\begin{array}{lll}\text { IL-17F } & 1.191642549 & 0.92987024\end{array}$

$\begin{array}{lll}\text { IL-17R } & 0.79896034 & 0.940454603\end{array}$

$\begin{array}{lll}\text { Procalcitonin } \quad 1.078606741 & 1.296472879\end{array}$

$\begin{array}{lll}\text { PSA-free } & 1.006366618 & 1.14188258\end{array}$

$\begin{array}{lll}\text { Shh N } & 1.259822603 & 1.013259418\end{array}$

$\begin{array}{lll}\text { Thyroglobulin } \quad 0.971384028 & 1.053278484\end{array}$

$\begin{array}{lll}\text { Ubiquitin+1 } & 1.362519593 & 1.016953326\end{array}$

CM from PF-stimulated hBMSCs induced the greatest chemotaxis as compared with any other group $(\mathrm{P}<0.0083)$, indicating that inflammatory microenvironment enhanced the secretion of bioactive components from hBMSCs. Taken together, these results are consistent with 


\section{Cellular Physiology and Biochemistry}

Cell Physiol Biochem 2014;33:905-919

\begin{tabular}{l|l}
\hline DOI: $10.1159 / 000358663$ & (C) 2014 S. Karger AG, Basel
\end{tabular}

www.karger.com/cpb

Xing et al.: Inflammatory Microenvironment Affects the Secretory Profile of Mesenchymal Stem Cells

Fig. 3. Spectral description of 262 cytokines using RayBio human antibody assay (AAHCYT-G4000) of CM from PF-stimulated hBMSCs (Column A), non-treated hBMSCs (Column B), and DMEM/F12 (Column C). The assay was repeated in quadruplicate. The relative levels of each protein in three groups of CM were normalized into a range from -1 to 1 , and then plotted by Matlab (version 7.0). The expression levels of 11 cytokines were significantly elevated in the CM of PF-stimulated hBMSCs, as compared with those in the CM from both untreated hBMSCs and DMEM/F12 alone. These differentially expressed cytokines were marked with red points in front of their names and included C-X-C motif ligand 16 (CXCL-16), Osteoprotegerin, growth-related oncogene (GRO), epithelial cell-derived neutrophil-activating peptide 78 (ENA-78), macrophage inflammatory protein-1-delta (MIP-1-delta), monocyte chemotactic protein 1 (MCP-1), MCP-2, MCP-3, Interleukin 6 (IL-6), granulocyte chemotactic peptide-2 (GCP-2), and Interleukin 2 receptor alpha (IL-2R alpha). CM, conditioned media. $\mathrm{PF}$, pro-inflammatory factors. hBMSCs, human bone-marrow mesenchymal stem cells. DMEM/F12, Dulbecco's modified Eagle's medium/F12.

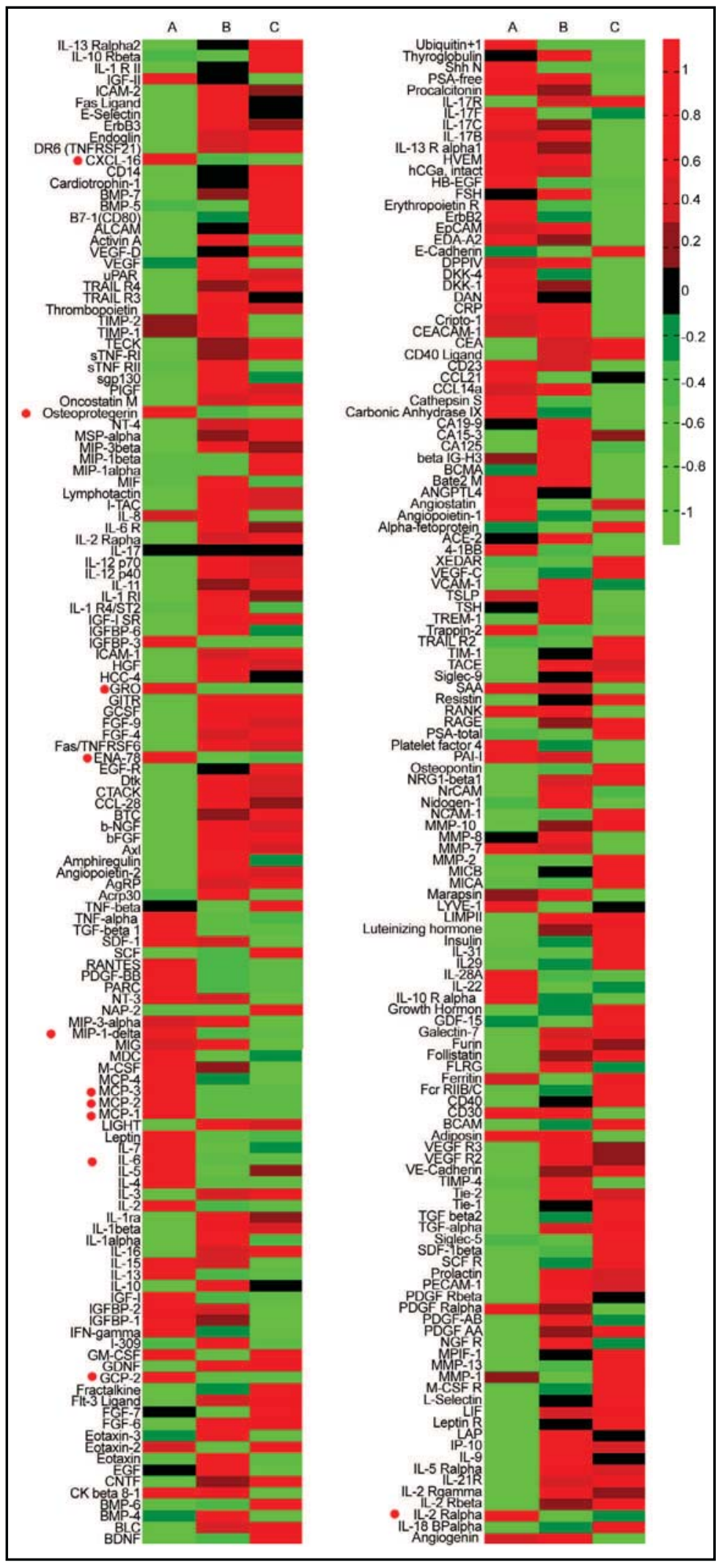

a growing literature suggesting that MSCs could release a series of cytokines and growth factors, and some of them are powerful MSCs chemoattractants [15, 22]. 
 \\ Xing et al.: Inflammatory Microenvironment Affects the Secretory Profile of Mesenchymal Stem Cells}

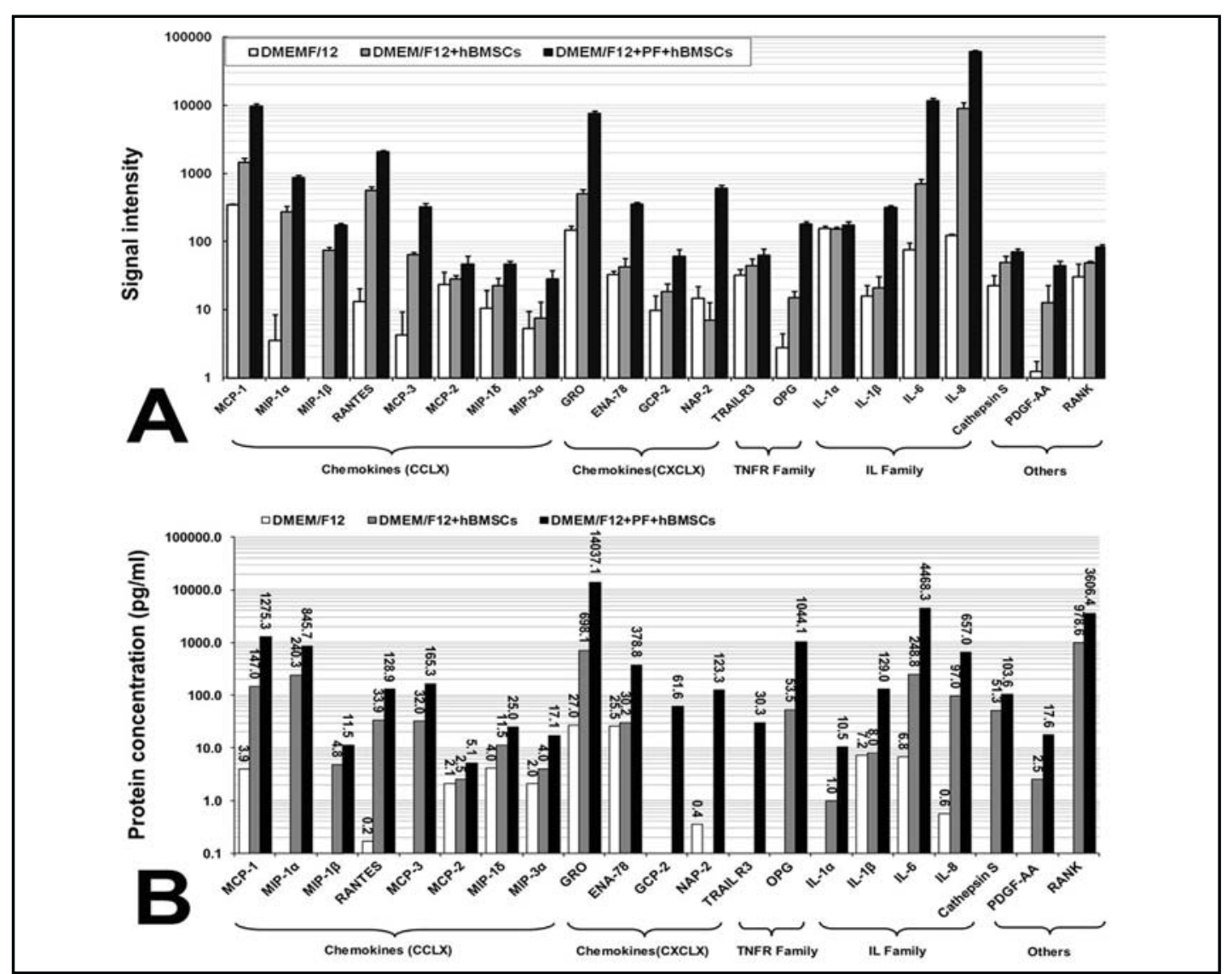

Fig. 4. Summary of signal intensities and protein concentrations of differentially expressed cytokines that associate with the migration of hBMSCs. Quantitative human cytokine assay was repeated in quadruplicate. Logarithmic transformation was performed on actual values for noticeable cognition. A: Compared to CM from non-treated hBMSCs, there were significant increases ( $p<0.05-0.01)$ in the relative levels of 21 cytokines in the CM from PF-stimulated hBMSCs. The other 21 cytokines detected (not shown in this figure) did not exhibit significant differences between these two groups. B: The concentrations of 21 differentially secreted proteins in different CM were measured, showed in logarithmic pattern. The actual mean concentrations were located above the columns. hBMSCs, human bone-marrow mesenchymal stem cells. CM, conditioned media. PF, pro-inflammatory factors. DMEM/F12, Dulbecco's modified Eagle's medium/F12.

\section{Preliminary screening of migration-related factors}

RayBio ${ }^{\circledR}$ Human Cytokine Antibody Assays were performed for preliminary cytokine screening. The expressions of 262 cytokines were simultaneously analyzed. The average fold change from CM of non-treated hBMSCs, whose mean was assigned a value of 1 , for all cytokines was reported in Table 3. As shown in Figure 3, culturing hBMSCs with PF induced significant increases in secretion of 11 cytokines. The levels of 2 proteins were elevated 4.09.9 fold, 3 proteins were increased 10.0-29.9 fold, and 3 proteins were stimulated greater than 30.0 fold (Table 3). Take DMEM/F12 as control (with mean assigned a value of 1), only 3 of these 11 cytokines (Osteoprotegerin, MIP-1-delta, GCP-2) showed a dramatic increase in expression $(>2$-fold increase and $p<0.05)$ due to the introduction of hBMSCs (Table 3 ). Taken together, these data reinforced the notions that hBMSCs secreted a variety of cytokines to recruit MSCs and inflammatory microenvironment is effective in stimulating cytokine production from hBMSCs.

Validation of chemokines involved in hBMSCs migration

After ANOVA tests on the relative levels of 262 cytokines, 11 cytokines were selected as differentially expressed (Fig. 3). The concentrations of them were then quantified by a 


\section{Cellular Physiology and Biochemistry}

Cell Physiol Biochem 2014;33:905-919

\begin{tabular}{l|l}
\hline DOI: $10.1159 / 000358663$ & C 2014 S. Karger AG, Basel
\end{tabular}

Xing et al.: Inflammatory Microenvironment Affects the Secretory Profile of Mesenchymal Stem Cells

multiplex-ELISA-based cytokine array. Despite these 11 cytokines, the levels of additional 31 cytokines were also evaluated, as most of them were known to be implicated in cell migration according to the existing literature. Only cytokines whose mean signal intensities were $>2$ fold above control levels and significantly different from control group $(\mathrm{p}<0.05)$ were included in the Figure 4. As compared with CM from non-treated hBMSCs, CM from PFstimulated hBMSCs showed more profound increases in secretion of 21 cytokines, including 9 of the 11 cytokines preliminarily screened except CXCL16 and IL-2R $\alpha$ (Fig. 4A). Thereinto, the maximal concentration occurred in GRO, with an average of $14.037 \mathrm{ng} / \mathrm{mL}$ for CM from PF-stimulated hBMSCs. Besides, the concentration of IL- 6 was $4.468 \mathrm{ng} / \mathrm{mL}$ in the CM from PF-stimulated hBMSCs and reduced by nearly half of the initial concentration $(10 \mathrm{ng} / \mathrm{mL})$ (Fig. 4B).

\section{Discussion}

In clinic, MSCs transplantation has been extensively performed for treating a wide array of diseases. Initially, their intrinsic multipotent differentiation properties generated the most interest, but more recently, their paracrine effect, which is manifested as the ability to define and manipulate the local microenvironment by releasing various bioactive molecules, is drawing the attention [23]. After local transplantation, donor MSCs interacted with surrounding microenvironment, resulting in recruitment of endogenous progenitor cells into the injury site to facilitate tissue regeneration $[4,6,7]$. Local inflammatory responses, incited by injury, have predominant responsibilities for host MSCs recruitment, with multiple inflammatory mediators (cytokines, chemokines and other potential chemoattractants) being involved [16]. Due to the presence of various bioactive cellular and molecular components, inflammatory microenvironment is likely to exert impacts on the secretome of transplanted MSCs and the relevant tropism of endogenous MSCs. A better understanding regarding this information is crucial for the comprehension of the cellular and molecular mechanisms governing MSCs transplantation, which remains the major bottleneck in the development of MSCs-based tissue engineering.

IL-1 $\beta$, IL-6, and TNF- $\alpha$ are representative molecules in the inflammatory microenvironment and play critical roles in the inflammatory diseases by triggering highly complicated biological cascades involving chemokines and cytokines $[15,16]$. Besides, each of them has been identified as a powerful MSCs chemoattractant [18-20]. Herein, we utilized IL-1 $\beta$, IL-6, and TNF- $\alpha$ to mimic the in vivo inflammatory microenvironment, as well as serve as a positive control for migration assay. For wound healing, the mobilization and homing of endogenous MSCs to the injured tissue is an essential but extremely complex process, and the molecular mechanisms are almost unknown $[3,4]$. In the present study, we demonstrated that cultured hBMSCs exhibited a potent capacity of attracting hBMSCs by secreting soluble chemokines, which was consistent with previous in vivo studies $[3,6,7]$. Such chemotactic power was comparable to that elicited by IL-1 $\beta$, IL-6, and TNF- $\alpha$, further validating the paracrine effects of transplanted MSCs. Moreover, the presence of inflammatory microenvironment (IL-1 $\beta$, IL-6, and TNF- $\alpha$ ) enhanced the host-hBMSCs-recruiting capacity of cultured hBMSCs, indicating promotional roles of inflammatory microenvironment in the paracrine effects of transplanted hBMSCs. Based on this, one can speculate that inflammatory microenvironment and resident transplanted MSCs interact with each other, bringing about synergetic effects to facilitate host MSCs homing to the transplantation site.

In order to rationally modulate and take advantage of the migration capacity of endogenous MSCs, the underlying mechanisms should be understood. Cell migration is generally attributed to chemotactic signals incited by growth factors or chemokines. Currently, the chemotactic signal pathways guiding the migration of MSCs are under lively investigation. A distinct set of soluble cytokines, including chemokines and growth factors, are emerging as dependable factors participating in the directed migration of MSCs [15]. Since the CM from PF-stimulated hBMSCs possessed a superior host-hBMSCs-recruiting 
Fig. 5. Schematic diagram of the potential effects of inflammatory microenvironment (with the presence of IL-1 $\beta$, IL- 6 , and TNF- $\alpha$ ) on the secretome of hBMSCs. Among the screened cytokines, the secretions of MIP-1 $\alpha$, RANTES, GRO, ENA-78, GCP-2, IL-8 and IL- 6 can be stimulated by both IL- $1 \beta$ and TNF- $\alpha$. Besides, IL-1 $\beta$ can increase the secretion of MIP- $3 \alpha$ and TNF- $\alpha$ while the hypersecretion of MCP- 1 is mainly attributed to the presence of TNF- $\alpha$. As with other differentially expressed cytokines, the secretory changes are difficult to explain according to the existing literature. Also, the effect of IL- 6 on the cytokine production from MSCs remains unknown.

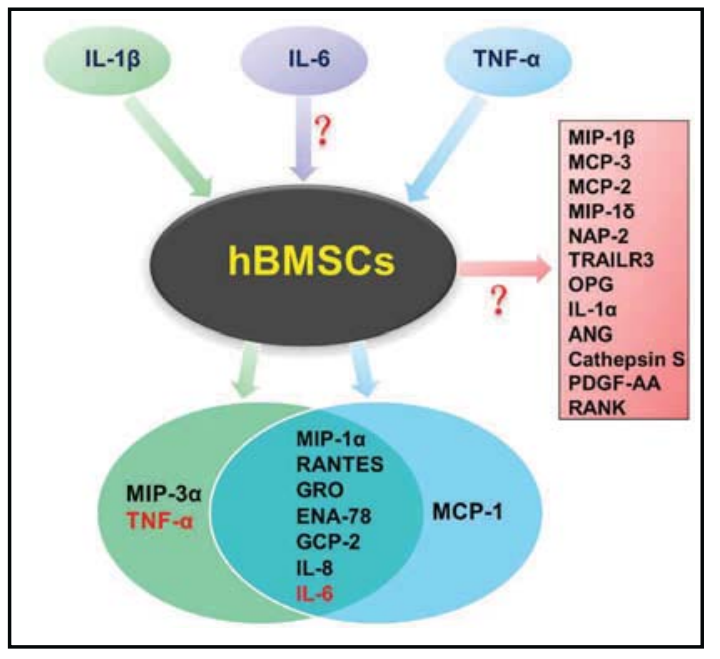

power, we hypothesised that such chemotactic disparity may be a representation of soluble chemoattractants with different concentrations therein. As showed by cytokine antibody microarrays, secretion of 21 proteins from transplanted hBMSCs was significantly increased by exposure to inflammatory microenvironment and included those involved in chemotaxis, invasion, cell signaling, cytoskeleton reorganization, and degradation of extracellular matrix. This indicated that the enhanced host-hBMSCs-recruiting activity of PF-stimulated hBMSCs was a synthetic result elicited by a set of bioactive molecules. It is worth noting that among various potent chemoattractants for stem cells, SDF-1 has attracted much attention in recruiting endogenous progenitors and guiding in situ regeneration. By signaling through the cognate receptor CXCR4, SDF-1 plays a predominant role in the activation, mobilization, homing and retention of CD34 ${ }^{+}$HSCs [24-27]. Several studies have demonstrated that local injection or delivery of SDF-1 can home MSCs to multitude target organs such as heart [28], kidney [29], brain [30], and bone [31]. Such capacity is further confirmed by successful applications of SDF-1 in tissue engineering strategies [32-34]. Thus, SDF-1 appears to be a major factor regulating MSCs migration. However, in this study, the SDF-1 production by transplanted hBMSCs was not increased in the inflammatory microenvironment, and the concentration was relatively lower than that in other studies where the introduction of SDF1 significantly enhanced MSCs migration. These findings not only dented the leading role of SDF-1, but also indicated that unlike the case for CD34 ${ }^{+} \mathrm{HSCs}$, it seemed an arduous task to define a major ligand/receptor system governing the migration of MSCs. Besides, we found that some of the identified cytokines, including IL-8, RANTES, MCP-1, MCP-2, and MCP-3, were also in close relationship with leukocyte migration [10]. As the mechanism underlying MSCs migration is still in infancy, these findings provided great inspiration for the current investigations taking leukocytes, but not HSCs, as research archetypes for MSCs trafficking.

A somewhat surprising finding from the present study was that GRO possessed the greatest level in the CM derived from PF-stimulated d hBMSCs. The GRO subgroup consists of three members, CXCL1/GRO- $\alpha$, CXCL2/GRO- $\beta$, and CXCL3/GRO- $\gamma$, and belongs to the IL-8 cytokine family [35]. This subfamily is a potent angiogenic chemokine group famous for stimulating chemotaxis of leukocyte, endothelial cells, as well as regulating inflammation and angiogenesis [36, 37]. Moreover, GRO have been demonstrated to be crucial in the mobilization and homing of stem cells [38-40]. During in vitro expansion, MSCs constitutively secrete GRO chemokines [35, 41, 42], which in turn regulate the biological behaviors of MSCs through binding to their cell-surface cognate receptor, CXCR2 [22, 36, 37]. Besides, GRO production from MSCs can be significantly increased by the stimulation of IL-1 $\beta$ and TNF- $\alpha[15,18,41]$. Taken together, it is reasonable to conclude that hypersecretion of GRO is a previously unrecognized molecular feature that specifically accompanies transplanted hBMSCs in inflammatory microenvironment and at least in part, GRO accounted for the enhanced capacity of transplanted hBMSCs in recruiting endogenous hBMSCs. Another 


\section{Cellular Physiology and Biochemistry}

Cell Physiol Biochem 2014;33:905-919

\begin{tabular}{l|l}
\hline DOI: $10.1159 / 000358663$ & (c) 2014 S. Karger AG, Basel
\end{tabular}

www.karger.com/cpb

Xing et al.: Inflammatory Microenvironment Affects the Secretory Profile of Mesenchymal Stem Cells

interesting finding was that the levels of IL- $1 \beta$ and TNF- $\alpha$ in the CM from PF-stimulated donor hBMSCs were very low or slightly higher, whilst, the concentration of IL- 6 was nearly half of the initial value and notably higher than that in the CM from non-treated hBMSCs. This indicated that hypersecretion of proteins might be mainly due to the presence of IL-1 $\beta$ and TNF- $\alpha$. Supporting this notion is the fact (as showed in Fig. 5) that IL-1 $\beta$ can stimulate MSCs to secrete MIP- $1 \alpha$, RANTES, MIP-3 $\alpha$, ENA-78, GCP-2, IL-8 as well as GRO $[18,41]$ and, TNF- $\alpha$ mainly accounts for hypersecretion of MIP-1 $\alpha$, RANTES, ENA-78, GCP-2, IL-8, GRO, and MCP$1[15,43]$. However, to the best of our knowledge, the influence of IL- 6 on the secretome profile of MSCs has not been reported. On the other hand, both IL-1 $\beta$ and TNF- $\alpha$ can increase the IL- 6 production from MSCs $[18,41,43]$. Considering the final concentration of IL- 6 , it is illogical to discount the secretagogue effect of IL-6, although further investigation is needed. Collectively, these reinforced the notion that the secretory variation of transplanted hBMSCs was a result from the synthetical actions of IL- $1 \beta$, IL- 6 and TNF- $\alpha$ and further complicated the relationship between inflammatory microenvironment and MSCs.

The major limitation of the present study is that the microarrays do not encompass all proteins probably involved in hBMSCs migration, and additional experiments (e.g. introduction of purified cytokines and blocking antibodies) aimed at further proofing the hBMSCs-recruiting roles of screened cytokines are lacking. However, anyway, it is a comprehensive comparison for fundamental screening and further studies exploring the biological behaviors of 21 identified cytokines are ongoing. Moreover, it is difficult to conclude whether the up-secreted 21 cytokines in the CM from PF-stimulated donor hBMSCs would be pathophysiologically important in vivo, but if their secretion could be modulated spatially and timely in a precise pattern, the administration of them would contribute substantially to the mobilization and migration of endogenous hBMSCs. It is also worth noting that the present study is encouraging in providing candidate bioactive molecules for researches in the field of in situ tissue regeneration, a tissue engineering concept focusing on recruiting host mesenchymal stem cells to injury site to conduct tissue regeneration [44]. As certain human recombinant bioactive molecules (e.g. BMP-2 and BMP-7) have been successfully used in clinic [45], with great enthusiasm, we here propose more in-depth researches aiming to development novel tissue-engineering products based on the present study. Actually, we are currently attempting to investigate the cross-talks between 21 identified cytokines and the surrounding transplantation microenvironment. Meanwhile, the downstream signal events in endogenous hBMSCs following the combination of these cytokines and their receptors are being identified, aiming to ravel the functional mechanism of transplanted-donor hBMSCs in vivo.

In this study, we analyzed the effects of inflammatory microenvironment on the chemotactic ability and secretome of transplanted hBMSCs. We observed that inflammatory microenvironment stimulated cultured hBMSCs to secrete more cytokines related to cell migration, which preliminarily uncovered the veil over the functional mechanism of transplanted hBMSCs. Moreover, 21 chemoattractant molecules were determined to be potentially involved in this effect. These new findings provided a basis for future studies on the interactions between transplanted donor cells and host microenvironment in the application of MSCs-based strategies. Further understanding of the biological effects of transplanted MSCs and their cytokines associated with migration of host MSCs will help to define and manage the roles of transplanted MSCs.

\section{Acknowledgments}

This work was supported by the National Natural Science Foundation of China (30900312,), the Foundation of Southwest Hospital (SWH2013JS07), and the Military Foundation (BWS11C040). 


\section{Cellular Physiology and Biochemistry}

Cell Physiol Biochem 2014;33:905-919

\begin{tabular}{l|l}
\hline DOI: $10.1159 / 000358663$ & (c) 2014 S. Karger AG, Basel
\end{tabular}

Xing et al.: Inflammatory Microenvironment Affects the Secretory Profile of Mesenchymal Stem Cells

\section{References}

1 Phinney DG, Prockop DJ: Concise review: Mesenchymal stem/multipotent stromal cells: The state of transdifferentiation and modes of tissue repair--current views. Stem Cells 2007;25:2896-2902.

-2 Fox JM, Chamberlain G, Ashton BA, Middleton J: Recent advances into the understanding of mesenchymal stem cell trafficking. Br J Haematol 2007;137:491-502.

-3 Tasso R, Fais F, Reverberi D, Tortelli F, Cancedda R: The recruitment of two consecutive and different waves of host stem/progenitor cells during the development of tissue-engineered bone in a murine model. Biomaterials 2010;31:2121-2129.

4 Tortelli F, Tasso R, Loiacono F, Cancedda R: The development of tissue-engineered bone of different origin through endochondral and intramembranous ossification following the implantation of mesenchymal stem cells and osteoblasts in a murine model. Biomaterials 2010;31:242-249.

-5 Hou T, Li Q Luo F, Xu J, Xie Z, Wu X, Zhu C: Controlled dynamization to enhance reconstruction capacity of tissue-engineered bone in healing critically sized bone defects: An in vivo study in goats. Tissue Eng Part A 2010;16:201-212.

-6 Tasso R, Augello A, Boccardo S, Salvi S, Carida M, Postiglione F, Fais F, Truini M, Cancedda R, Pennesi G: Recruitment of a host's osteoprogenitor cells using exogenous mesenchymal stem cells seeded on porous ceramic. Tissue Eng Part A 2009;15:2203-2212.

-7 Zhou Y, Fan W, Prasadam I, Crawford R, Xiao Y: Implantation of osteogenic differentiated donor mesenchymal stem cells causes recruitment of host cells. J Tissue Eng Regen Med 2012; DOI: 10.1002/ term.1619

8 Chen FM, Wu LA, Zhang M, Zhang R, Sun HH: Homing of endogenous stem/progenitor cells for in situ tissue regeneration: Promises, strategies, and translational perspectives. Biomaterials 2011;32:3189-3209.

-9 Gerstenfeld LC, Cullinane DM, Barnes GL, Graves DT, Einhorn TA: Fracture healing as a post-natal developmental process: Molecular, spatial, and temporal aspects of its regulation. J Cell Biochem 2003;88:873-884.

10 Spaeth E, Klopp A, Dembinski J, Andreeff M, Marini F: Inflammation and tumor microenvironments: Defining the migratory itinerary of mesenchymal stem cells. Gene Ther 2008;15:730-738.

11 Sasaki M, Abe R, Fujita Y, Ando S, Inokuma D, Shimizu H: Mesenchymal stem cells are recruited into wounded skin and contribute to wound repair by transdifferentiation into multiple skin cell type. J Immunol 2008;180:2581-2587.

12 Barnes GL, Kostenuik PJ, Gerstenfeld LC, Einhorn TA: Growth factor regulation of fracture repair. J Bone Miner Res 1999;14:1805-1815.

13 Dimitriou R, Tsiridis E, Giannoudis PV: Current concepts of molecular aspects of bone healing. Injury 2005;36:1392-1404.

14 Honczarenko M, Le Y, Swierkowski M, Ghiran I, Glodek AM, Silberstein LE: Human bone marrow stromal cells express a distinct set of biologically functional chemokine receptors. Stem Cells 2006;24:1030-1041.

15 Ponte AL, Marais E, Gallay N, Langonne A, Delorme B, Herault O, Charbord P, Domenech J: The in vitro migration capacity of human bone marrow mesenchymal stem cells: Comparison of chemokine and growth factor chemotactic activities. Stem Cells 2007;25:1737-1745.

16 Mountziaris PM, Mikos AG: Modulation of the inflammatory response for enhanced bone tissue regeneration. Tissue Eng Part B Rev 2008;14:179-186.

17 Locksley RM, Killeen N, Lenardo MJ: The tnf and tnf receptor superfamilies: Integrating mammalian biology. Cell 2001;104:487-501.

18 Carrero R, Cerrada I, Lledo E, Dopazo J, Garcia-Garcia F, Rubio MP, Trigueros C, Dorronsoro A, Ruiz-Sauri A, Montero JA, Sepulveda P: Il1beta induces mesenchymal stem cells migration and leucocyte chemotaxis through nf-kappab. Stem Cell Rev 2012;8:905-916.

-19 Rattigan Y, Hsu JM, Mishra PJ, Glod J, Banerjee D: Interleukin 6 mediated recruitment of mesenchymal stem cells to the hypoxic tumor milieu. Exp Cell Res 2010;316:3417-3424.

20 Xiao Q, Wang SK, Tian H, Xin L, Zou ZG, Hu YL, Chang CM, Wang XY, Yin QS, Zhang XH, Wang LY: Tnf-alpha increases bone marrow mesenchymal stem cell migration to ischemic tissues. Cell Biochem Biophys 2012;62:409-414. 


\section{Cellular Physiology and Biochemistry}

Cell Physiol Biochem 2014;33:905-919

\begin{tabular}{l|l}
\hline DOI: $10.1159 / 000358663$ & (c) 2014 S. Karger AG, Basel
\end{tabular}

Xing et al.: Inflammatory Microenvironment Affects the Secretory Profile of Mesenchymal Stem Cells

21 Ries C, Egea V, Karow M, Kolb H, Jochum M, Neth P: Mmp-2, mt1-mmp, and timp-2 are essential for the invasive capacity of human mesenchymal stem cells: Differential regulation by inflammatory cytokines. Blood 2007;109:4055-4063.

-22 Ringe J, Strassburg S, Neumann K, Endres M, Notter M, Burmester GR, Kaps C, Sittinger M: Towards in situ tissue repair: Human mesenchymal stem cells express chemokine receptors cxcr1, cxcr2 and ccr2, and migrate upon stimulation with cxcl8 but not ccl2. J Cell Biochem 2007;101:135-146.

23 Granero-Molto F, Myers TJ, Weis JA, Longobardi L, Li T, Yan Y, Case N, Rubin J, Spagnoli A: Mesenchymal stem cells expressing insulin-like growth factor-i (mscigf) promote fracture healing and restore new bone formation in irs1 knockout mice: Analyses of mscigf autocrine and paracrine regenerative effects. Stem Cells 2011;29:1537-1548.

-24 Peled A, Petit I, Kollet O, Magid M, Ponomaryov T, Byk T, Nagler A, Ben-Hur H, Many A, Shultz L, Lider O, Alon R, Zipori D, Lapidot T: Dependence of human stem cell engraftment and repopulation of nod/scid mice on cxcr4. Science 1999;283:845-848.

-25 Grunewald M, Avraham I, Dor Y, Bachar-Lustig E, Itin A, Jung S, Chimenti S, Landsman L, Abramovitch R, Keshet E: Vegf-induced adult neovascularization: Recruitment, retention, and role of accessory cells. Cell 2006;124:175-189.

26 Ceradini DJ, Kulkarni AR, Callaghan MJ, Tepper OM, Bastidas N, Kleinman ME, Capla JM, Galiano RD, Levine JP, Gurtner GC: Progenitor cell trafficking is regulated by hypoxic gradients through hif-1 induction of sdf- 1 . Nat Med 2004;10:858-864.

27 Jin DK, Shido K, Kopp HG, Petit I, Shmelkov SV, Young LM, Hooper AT, Amano H, Avecilla ST, Heissig B, Hattori K, Zhang F, Hicklin DJ, Wu Y, Zhu Z, Dunn A, Salari H, Werb Z, Hackett NR, Crystal RG, Lyden D, Rafii S: Cytokine-mediated deployment of sdf-1 induces revascularization through recruitment of cxcr4+ hemangiocytes. Nat Med 2006;12:557-567.

28 Abbott JD, Huang Y, Liu D, Hickey R, Krause DS, Giordano FJ: Stromal cell-derived factor-1alpha plays a critical role in stem cell recruitment to the heart after myocardial infarction but is not sufficient to induce homing in the absence of injury. Circulation 2004;110:3300-3305.

29 Liu H, Liu S, Li Y, Wang X, Xue W, Ge G, Luo X: The role of sdf-1-cxcr4/cxcr7 axis in the therapeutic effects of hypoxia-preconditioned mesenchymal stem cells for renal ischemia/reperfusion injury. PLoS One 2012;7:e34608.

-30 Wang Y, Deng Y, Zhou GQ: Sdf-1alpha/cxcr4-mediated migration of systemically transplanted bone marrow stromal cells towards ischemic brain lesion in a rat model. Brain Res 2008;1195:104-112.

-31 Kitaori T, Ito H, Schwarz EM, Tsutsumi R, Yoshitomi H, Oishi S, Nakano M, Fujii N, Nagasawa T, Nakamura T: Stromal cell-derived factor $1 /$ cxcr4 signaling is critical for the recruitment of mesenchymal stem cells to the fracture site during skeletal repair in a mouse model. Arthritis Rheum 2009;60:813-823.

32 Shen W, Chen X, Chen J, Yin Z, Heng BC, Chen W, Ouyang HW: The effect of incorporation of exogenous stromal cell-derived factor-1 alpha within a knitted silk-collagen sponge scaffold on tendon regeneration. Biomaterials 2010;31:7239-7249.

33 Thevenot PT, Nair AM, Shen J, Lotfi P, Ko CY, Tang L: The effect of incorporation of sdf-1alpha into plga scaffolds on stem cell recruitment and the inflammatory response. Biomaterials 2010;31:3997-4008.

-34 He X, Ma J, Jabbari E: Migration of marrow stromal cells in response to sustained release of stromal-derived factor-1alpha from poly(lactide ethylene oxide fumarate) hydrogels. Int J Pharm 2010;390:107-116.

-35 Chen HW, Chen HY, Wang LT, Wang FH, Fang LW, Lai HY, Chen HH, Lu J, Hung MS, Cheng Y, Chen MY, Liu SJ, Chong P, Lee OK, Hsu SC: Mesenchymal stem cells tune the development of monocyte-derived dendritic cells toward a myeloid-derived suppressive phenotype through growth-regulated oncogene chemokines. J Immunol 2013;190:5065-5077.

-36 Loukinova E, Dong G, Enamorado-Ayalya I, Thomas GR, Chen Z, Schreiber H, Van Waes C: Growth regulated oncogene-alpha expression by murine squamous cell carcinoma promotes tumor growth, metastasis, leukocyte infiltration and angiogenesis by a host cxc receptor-2 dependent mechanism. Oncogene 2000;19:3477-3486.

37 Keeley EC, Mehrad B, Strieter RM: Cxc chemokines in cancer angiogenesis and metastases. Adv Cancer Res 2010;106:91-111.

- 38 Kee HJ, Sohn IS, Nam KI, Park JE, Qian YR, Yin Z, Ahn Y, Jeong MH, Bang YJ, Kim N, Kim JK, Kim KK, Epstein JA, Kook H: Inhibition of histone deacetylation blocks cardiac hypertrophy induced by angiotensin ii infusion and aortic banding. Circulation 2006;113:51-59. 
Xing et al.: Inflammatory Microenvironment Affects the Secretory Profile of Mesenchymal Stem Cells

39 Frangogiannis NG, Smith CW, Entman ML: The inflammatory response in myocardial infarction. Cardiovasc Res 2002;53:31-47.

40 Kocher AA, Schuster MD, Bonaros N, Lietz K, Xiang G, Martens TP, Kurlansky PA, Sondermeijer H, Witkowski P, Boyle A, Homma S, Wang SF, Itescu S: Myocardial homing and neovascularization by human bone marrow angioblasts is regulated by il-8/gro cxc chemokines. J Mol Cell Cardiol 2006;40:455-464.

41 Moorefield EC, McKee EE, Solchaga L, Orlando G, Yoo JJ, Walker S, Furth ME, Bishop CE: Cloned, cd117 selected human amniotic fluid stem cells are capable of modulating the immune response. PLoS one 2011;6:e26535.

42 Velpula KK, Dasari VR, Rao JS: The homing of human cord blood stem cells to sites of inflammation: Unfolding mysteries of a novel therapeutic paradigm for glioblastoma multiforme. Cell Cycle 2012;11:23032313.

43 Lee MJ, Kim J, Kim MY, Bae YS, Ryu SH, Lee TG, Kim JH: Proteomic analysis of tumor necrosis factor-alphainduced secretome of human adipose tissue-derived mesenchymal stem cells. J Proteome Res 2010;9:17541762.

44 Ko IK, Ju YM, Chen T, Atala A, Yoo JJ, Lee SJ: Combined systemic and local delivery of stem cell inducing/ recruiting factors for in situ tissue regeneration. FASEB J 2012;26:158-168.

45 Steinert AF, Rackwitz L, Gilbert F, Noth U, Tuan RS: Concise review: The clinical application of mesenchymal stem cells for musculoskeletal regeneration: Current status and perspectives. Stem Cells Transl Med 2012;1:237-247. 